\title{
Serum interleukin-23 protects, whereas methotrexate treatment stimulates selected components of the metabolic syndrome in patients with SAPHO syndrome
}

\author{
Hanna Przepiera-Będzak¹, Katarzyna Fischer ${ }^{2}$, Marek Brzosko
}

\author{
${ }^{1}$ Department of Rheumatology, Internal Medicine and Geriatrics, Pomeranian Medical \\ University, Szczecin, Poland \\ 2Independent Laboratory of Rheumatic Diagnostics, Pomeranian Medical University, \\ Szczecin, Poland
}

Submitted: 4 September 2017

Accepted: 4 November 2017

Arch Med Sci 2021; 17 (1): 120-126

DOI: https://doi.org/10.5114/aoms.2018.76953

Copyright (c) 2018 Termedia \& Banach

\section{Abstract}

Introduction: The aim of the study was to evaluate the impact of disease activity, selected serum cytokines, and therapy on metabolic syndrome (MetS) components in patients with synovitis, acne, pustulosis, hyperostosis, and osteitis (SAPHO) syndrome.

Material and methods: We studied 46 SAPHO patients (40 women, 6 men). We recorded age, sex, disease duration, arthritis localization, type of skin changes, bone scintigraphy results, comorbidities, BASDAI, VAS, and treatment. We measured erythrocyte sedimentation rate, C-reactive protein, lipid profile, serum IL-6, IL-18, IL-23, endothelin-1, vascular endothelial growth factor, and epidermal growth factor (EGF).

Results: $97.8 \%$ of patients had sternoclavicular joint arthritis, $91.3 \%$ of patients palmoplantar pustulosis. In $65.2 \%$ of SAPHO patients skin changes and arthritis started simultaneously. Apart from non-steroidal anti-inflammatory drugs, patients were treated with methotrexate $(41.3 \%)$, sulfasalazine $(41.3 \%)$, and antibiotics $(39.1 \%) .19 .5 \%$ of patients met MetS criteria. Serum IL-23 correlated positively with total cholesterol (TC; $p=0.02$ ) and high-density lipoprotein cholesterol (HDL-C) $(p=0.01)$ in the SAPHO group. There was a negative correlation between HDL-C and BASDAI ( $p=$ $0.02)$. Patients treated with methotrexate had higher triglyceride $(p=0.01)$ and low-density lipoprotein cholesterol (LDL-C) $(p=0.01)$ levels. There was a negative correlation between TC and EGF $(p=0.03)$. Increased prevalence of autoimmune diseases and depression was observed in SAPHO patients. Conclusions: Serum IL-23 protects, whereas methotrexate treatment stimulates selected components of the MetS in patients with SAPHO syndrome.

Key words: interleukin-23, lipid profile, metabolic syndrome, methotrexate, SAPHO.

\section{Introduction}

Synovitis, acne, pustulosis, hyperostosis, and osteitis (SAPHO) syndrome is a very rare musculoskeletal disease that encompasses a variety of osteoarticular disorders accompanied by dermatoses and was introduced by Chamot et al. [1] in 1987. The diagnostic criteria for SAPHO syndrome were developed by Kahn et al. [2] in 1994. SAPHO syndrome is classified along two different spectrums in adults: pustulo-hyperostotic

\author{
Corresponding author: \\ Hanna Przepiera-Będzak MD, \\ $\mathrm{PhD}$, \\ Department of Rheumatology \\ Internal Medicine and \\ Geriatrics \\ Pomeranian Medical \\ University \\ 1 Unii Lubelskiej St \\ 71-252 Szczecin, Poland \\ Phone: +48 914253321 \\ Fax: +48 914253344 \\ E-mail: hannapb@pum.edu.p
}


psoriatic spondyloarthritis (PPHS) and chronic recurrent multifocal osteomyelitis (CRMO) [3].

There is some debate whether SAPHO syndrome is a form of spondyloarthritis (SpA) or psoriatic arthritis (PsA), or a disease in its own right $[4,5]$.

The first sign of arthritis is anterior chest wall involvement, most often the sternoclavicular joints and attachments of the first ribs to the sternum. The typical skin lesions are palmoplantar pustulosis (PPP), severe acne or acne inversa (hidradenitis suppurativa) [1-3, 6, 7].

In SAPHO syndrome, in addition to the clinical assessment, imaging studies are important in diagnosis. In early stages of the disease, bone scintigraphy is useful. On computed tomography (CT), erosions, sclerotic changes, and new bone formation are observed [8-10].

The cause of SAPHO is unknown, and no standard treatment protocols are available. Propionibacterium acne may play a role as a potential antigenic trigger [11-13]. The syndrome is often chronic and eventually self-healing.

Several pro-inflammatory cytokines such as interleukin-6 (IL-6), interleukin-18 (IL-18), interleukin-23 (IL-23) and cytokines involved in angiogenesis such as vascular endothelial growth factor (VEGF), epidermal growth factor (EGF), and proinflammatory peptide endothelin-1 (ET-1) are considered to be involved in the inflammatory process in SpA [14-16].

A variety of studies have suggested that patients with PsA have an increased risk of metabolic syndrome (MetS), which is a clustering of cardiovascular risk factors, such us obesity, hypertension, dyslipidemia, and insulin resistance $[17$, 18]. There are no data concerning the risk of MetS in patients with SAPHO syndrome.

The aim of the study was to evaluate the impact of disease activity, selected serum cytokines, and therapy on MetS components in patients with SAPHO syndrome.

\section{Material and methods}

This study was approved by the local ethics committee of the Pomeranian Medical University in Szczecin. Informed consent was obtained from all patients.

We studied 46 SAPHO patients and included 30 healthy volunteers as controls. All patients were Caucasian. The diagnosis of SAPHO syndrome was made according to the Kahn criteria [2].

The following data were recorded: age, sex, disease duration, type of joint involvement, type of skin changes, bone scintigraphy results, comorbidities, cigarette smoking, and treatment.

Weight and height were measured to calculate the body mass index (BMI, $\left.\mathrm{kg} / \mathrm{m}^{2}\right)$. The waist and hip circumference were measured to calculate the waist/hip ratio (WHR).
The patient's pain due to the disease at the time of examination was assessed using a visual analogue scale (VAS).

We also assessed the Bath Ankylosing Spondylitis Disease Activity Index (BASDAI). This index has a possible score of 0-10, with a higher score indicating greater disease activity [19].

Blood was taken after at least $8 \mathrm{~h}$ of fasting for assessment of the erythrocyte sedimentation rate (ESR, $\mathrm{mm} / \mathrm{h}$, Westergren method), C-reactive protein (CRP, $\mathrm{mg} / \mathrm{dl}$ ) (turbidimetric nephelometry, rate reaction), total cholesterol (TC, $\mathrm{mmol} / \mathrm{l})$, high-density lipoprotein cholesterol (HDL-C, mmol/l), low-density lipoprotein cholesterol (LDL-C, mmol/l), and triglycerides (TG, $\mathrm{mmol} / \mathrm{l}$ ), measured according to standard procedures. HLA-B27 was determined using a BD Biosciences test (Becton, Dickinson and Company BD Biosciences, San Jose, CA, USA) based on flow cytometry and a BD FACSCanto II apparatus. Rheumatoid factor (RF) was measured using an ELISA kit.

In 34 SAPHO patients serum was stored at $-80^{\circ} \mathrm{C}$ until analysis for IL-6, IL-18, IL-23, ET-1, VEGF, and EGF using a sensitive sandwich ELISA method: Human IL-6 Immunoassay Quantikine ELISA kit (the minimum detectable dose less than $0.7 \mathrm{pg} / \mathrm{ml}$ ) (R\&D Systems, Minneapolis, United States), Human IL-18 Quantitative ELISA kit (the minimum detectable dose less than $12.5 \mathrm{pg} / \mathrm{ml}$ ) (MBL, Nagoya, Japan), Human IL-23 Immunoassay Quantikine ELISA kit (the minimum detectable dose less than $6.8 \mathrm{pg} / \mathrm{ml}$ ), Human ET-1 Immunoassay Quantikine ELISA kit (the minimum detectable dose less than $0.087 \mathrm{pg} / \mathrm{ml}$ ), Human VEGF Immunoassay Quantikine ELISA kit (the minimum detectable dose less than $5.0 \mathrm{pg} / \mathrm{ml}$ ), and Human EGF Immunoassay Quantikine ELISA kit (the minimum detectable dose less than $0.7 \mathrm{pg} / \mathrm{ml}$ ) (R\&D Systems, Minneapolis, United States). All analyses and calibrations were performed in duplicate according to the manufacturer's instructions, and read using a BioTek PowerWaveXS spectrophotometer (Winooski, VT, USA).

The NCEP-ACT III criteria were used to identify subjects with MetS [20].

\section{Statistical analysis}

Data distributions were assessed using the Kolmogorov-Smirnov test. Data are described as mean \pm standard deviation and median (Q1, Q3). The $R$ values of correlations were determined and $p<0.05$ was considered significant. The groups were compared using Student's $t$-test, the Mann-Whitney $U$ test and the Kruskal-Wallis test. To assess parameters, Pearson's chi-squared test $\left(\chi^{2}\right)$, logistic regression analysis, and step-wise analysis were performed. The level of significance was set at $p<0.05$. The statistical analysis was 
performed using Statistica version 8.0 (StatSoft, Inc., Tulsa, OK, USA).

\section{Results}

The clinical and laboratory characteristics of the study group and controls are presented in Table I.

The most prevalent comorbidity was hypertension, followed by hypothyroidism, diabetes and depression (Table II).

All patients were treated with non-steroidal antiinflammatory drugs (NSAIDs), which were effective (on the basis of the reduction of clinical and laboratory activity of the disease) only in $17.4 \%$ of patients. In $41.3 \%$ of patients, sulfasalazine $1 \mathrm{~g} /$ day or methotrexate (MTX) $15 \mathrm{mg} /$ day was added. In $39.1 \%$ of patients, with active skin changes, antibiotics were added (doxycycline $1 \times 100 \mathrm{mg} /$ day (50\%) or azithromycin $2 \times 500 \mathrm{mg}$ weekly $(50 \%))$ (Table III).

No significant correlations were found between disease duration, VAS and BASDAI with serum levels of the selected cytokines (all $p>0.05$ ).

Serum IL-6 levels were higher in SAPHO patients than in the control group $(p=0.09)$ (Table I). There was a positive correlation between IL- 6 and CRP $(r=0.72 ; p=0.00005)$, and ESR $(r=0.53$; $p=0.005)$ and WHR $(r=0.82 ; p=0.0002)$.

Serum IL-18 levels were higher in SAPHO patients than in controls $(p=0.01)$. Serum IL-23 levels were higher in SAPHO patients than in the control group $(p=0.01)$. No differences were found between SAPHO patients and controls in terms of ET-1, VEGF, and EGF levels (all $p>0.05$ ) (Table I).

No correlations were found between serum IL-18, IL-23, VEGF, EGF, ET-1 and disease activity assessed by VAS, CRP, ESR, BASDAI in the SAPHO group (all $p>0.05$ ) (data not shown).

SAPHO patients had higher BMI than controls ( $p=0.02$ ) (Table I). Metabolic syndrome criteria were present in $9(19.5 \%)$ patients. SAPHO patients treated with MTX compared to those not treated with MTX had a higher BMI $(28.4 \pm 3.9$ vs. $26.1 \pm 3.3, p=0.05)$ and higher prevalence of MetS ( $26.3 \%$ vs. $7.4 \%, p=0.04)$. There were no differences between serum markers of the lipid profile between SAPHO and controls (all $p>0.05$ ).

There was a positive correlation of TC with VAS $(r=0.55 ; p=0.04)$ and with IL-23 $(r=0.63$; $p=0.02)$ in SAPHO patients. SAPHO patients with VAS > 40 had higher TC levels compared to those with VAS $\leq 40(235.3 \pm 30.6$ vs. $177.0 \pm 37.2$ $\mathrm{mmol} / \mathrm{l}, p=0.004)$. There was a negative correlation between TC and EGF in SAPHO patients ( $r=$ $-0.74 ; p=0.03$ ).

There was a negative correlation of HDL-C with age $(r=-0.41 ; p=0.04)$, BASDAI $(r=-0.51$; $p=0.02)$, and with BMI $(r=-0.65 ; p=0.001)$ in SAPHO patients. SAPHO patients with BASDAI
$>4$ had lower HDL-C levels compared to those with BASDAI $\leq 4$ (54.2 \pm 14.2 vs. $68.8 \pm 11.6 \mathrm{mmol} / \mathrm{l}$, $p=0.02)$. SAPHO patients with $\mathrm{BMI}>30.0 \mathrm{com}-$ pared to those with $\mathrm{BMI} \leq 30.0$ had lower HDL-C levels $(41.0 \pm 13.0$ vs. $67.5 \pm 11.9 \mathrm{mmol} / \mathrm{l}, p=$ $0.009)$. There was a positive correlation between HDL-C and IL-23 ( $r=0.67 ; p=0.01)$.

There was a positive correlation of LDL-C with ESR $(r=0.45 ; p=0.04)$, ET-1 $(r=0.47 ; p=0.04)$, and with EGF $(r=0.66 ; p=0.01)$ in SAPHO patients. SAPHO patients with VAS $>40$ had higher LDL-C levels compared to those with VAS $\leq 40$ (147.6 \pm 30.0 vs. $102.0 \pm 32.5 \mathrm{mmol} / \mathrm{l}, p=0.01)$. SAPHO patients treated with MTX had higher LDL-C levels compared to those not treated with MTX (151.5 \pm 30.7 vs. $120.5 \pm 35.2 \mathrm{mmol} / \mathrm{l}, p=0.04)$. $\mathrm{SAPHO}$ patients with $\mathrm{BMI}>30.0$ compared to those with $\mathrm{BMI} \leq 30.0 \mathrm{~kg} / \mathrm{m}^{2}$ had higher LDL-C levels $(170.3 \pm 27.0$ vs. $126.6 \pm 32.2 \mathrm{mmol} / \mathrm{l}, p=0.02)$.

There was also a positive correlation of TG with age $(r=0.44 ; p=0.03)$, BASDAI $(r=0.51 ; p=$ $0.02)$, and with BMI $(r=0.52 ; p=0.01)$ in SAPHO patients. SAPHO patients with BASDAI > 4 had higher TG levels compared to those with BASDAl $\leq 4(167.3 \pm 96.5$ vs. $93.0 \pm 34.4 \mathrm{mmol} / \mathrm{l}, p=0.01)$. $\mathrm{SAPHO}$ patients with $\mathrm{BMI}>25.0 \mathrm{~kg} / \mathrm{m}^{2}$ compared to those with $\mathrm{BMI} \leq 25.0 \mathrm{~kg} / \mathrm{m}^{2}$ had higher TG levels (166.7 \pm 89.2 vs. $98.2 \pm 24.6 \mathrm{mmol} / \mathrm{l}, p=0.01)$. SAPHO patients treated with MTX had higher TG levels compared to those not treated with MTX $(159.9 \pm 82.3$ vs. $93.3 \pm 44.6 \mathrm{mmol} / \mathrm{l}, p=0.01)$.

To assess parameters associated with serum IL-6, IL-18, IL-23, ET-1, VEGF, and EGF, Pearson's chi-squared test $\left(\chi^{2}\right)$, logistic regression analysis, and step-wise analysis were performed and no significant associations were found (all $p>0.05$ ). There was no effect of age or sex on the results of the study.

There was no influence of treatment with NSAIDs, sulfasalazine or antibiotics on lipid profile markers in SAPHO patients.

\section{Discussion}

In our study, we investigated SAPHO syndrome, a rare musculoskeletal disease, and found that SAPHO was more common in middle-aged women, and that the most prevalent skin change was PPP. Other authors have confirmed the same associations [5, 21-23].

In our previously published study, we found that SAPHO patients with PPP compared with SpA patients without PPP had shorter disease durations, lower prevalence of HLA-B27 antigen, and lower BASDAI. Additionally, in SAPHO patients increased serum levels of IL-18 were associated with increased risk of PPP [24].

Serum IL-6 is a pro-inflammatory cytokine considered to be related to obesity development [25]. 
Table I. Clinical and laboratory characteristics of the study group and controls

\begin{tabular}{|c|c|c|}
\hline Assessed parameter & $\begin{array}{c}\text { SAPHO } \\
\text { syndrome patients }(n=46) \\
\text { Mean } \pm \text { SD; } n(\%), \text { median }(Q 1, Q 3)\end{array}$ & $\begin{array}{c}\text { Controls } \\
(n=30) \\
\text { Mean } \pm \text { SD, median }(\mathrm{Q} 1, \mathrm{Q} 3)\end{array}$ \\
\hline Sex & Female 40 , male 6 & Female 19 , male 11 \\
\hline Age [years] & $51.0 \pm 12.1$ & $43.5 \pm 9.4$ \\
\hline Disease duration [years] & $2.9 \pm 2.6$ & - \\
\hline Duration of skin changes [years] & 6.1 & - \\
\hline $\begin{array}{l}\text { Sternoclavicular joint involvement } \\
\text { on physical examination: }\end{array}$ & $45(97.8)$ & - \\
\hline Unilateral & $26(56.5)$ & \\
\hline Bilateral & $19(41.3)$ & \\
\hline Shoulder joint involvement & $19(41.3)$ & - \\
\hline Palmoplantar pustulosis & $42(91.3)$ & - \\
\hline Acne & $3(6.5)$ & - \\
\hline Lack of skin changes & $1(2.2)$ & - \\
\hline $\begin{array}{l}\text { Skin changes preceded onset } \\
\text { of arthritis }\end{array}$ & $13(28.3)$ & - \\
\hline $\begin{array}{l}\text { Skin changes and arthritis started } \\
\text { simultaneously }\end{array}$ & $30(65.2)$ & - \\
\hline $\begin{array}{l}\text { Arthritis preceded onset of skin } \\
\text { changes }\end{array}$ & $2(4.3)$ & - \\
\hline VAS $[\mathrm{mm}]$ & $47.9 \pm 20.5$ & 0 \\
\hline BASDAI & $4.3 \pm 2.2$ & 0 \\
\hline Smoking & $13(28.2 \%)$ & 0 \\
\hline BMI & $27.2 \pm 3.9$ & $24.2 \pm 3.4$ \\
\hline WHR & $0.81 \pm 0.17$ & - \\
\hline $\begin{array}{l}\text { Increased tracer uptake on bone } \\
\text { scintigraphy in sternoclavicular } \\
\text { joints (positive/done) (\%) }\end{array}$ & $39 / 45(86.6)$ & - \\
\hline $\begin{array}{l}\text { Increased tracer uptake on bone } \\
\text { scintigraphy in sacroiliac joints } \\
\text { (positive/done) (\%) }\end{array}$ & $7 / 45(15.6)$ & - \\
\hline RF negative & $46(100)$ & - \\
\hline HLA B-27 (positive/done (\%)) & 4/23 (17.4) & - \\
\hline $\mathrm{ESR}[\mathrm{mm} / \mathrm{h}]$ & $22.1 \pm 19.6$ & $9.0(2.0,16.0)$ \\
\hline $\mathrm{CRP}[\mathrm{mg} / \mathrm{l}]$ & $7.5 \pm 8.9$ & 0 \\
\hline Total cholesterol [mmol/l] & $220.3 \pm 49.1$ & $229.0 \pm 40.0$ \\
\hline HDL cholesterol [mmol/l] & $61.5 \pm 16.2$ & $62.5 \pm 10.1$ \\
\hline LDL cholesterol [mmol/l] & $137.5 \pm 43.7$ & $139.2 \pm 33.8$ \\
\hline Triglyceride [mmol/l] & $131.9 \pm 68.9$ & $135.8 \pm 60.3$ \\
\hline IL-6 [pg/ml] & $2.5(1.0,6.61)$ & $1.15(0.6,1.5)$ \\
\hline IL-18 [pg/ml] & $259.4(193.3,339.0)$ & $198.9(165.1,271.5)$ \\
\hline IL-23 [pg/ml] & $0.0(0.0,0.3)$ & $0.0(0.0,0.0)$ \\
\hline ET-1 [pg/ml] & $1.49 \pm 0.64$ & $1.47 \pm 0.57$ \\
\hline VEGF $[\mathrm{pg} / \mathrm{ml}]$ & $320.0(240.0,375.0)$ & $270.0(180.0,445.0)$ \\
\hline $\mathrm{EGF}[\mathrm{pg} / \mathrm{ml}]$ & $93.0(58.0,168.0)$ & $81.0(38.0,134.0)$ \\
\hline
\end{tabular}

Data are presented as number (\%), mean \pm standard deviation, median (Q1, Q3). BASDAI - Bath Ankylosing Spondylitis Disease Activity Index, CRP - C-reactive protein, EGF - epidermal growth factor, ESR - erythrocyte sedimentation rate, ET-1 - endothelin-1, F - female, IL-6 - interleukin-6, IL-18 - interleukin-18, IL-23 - interleukin-23; M - male, $n$ - number of patients, SAPHO - synovitis acne pustulosis hyperostosis osteitis syndrome, VAS pain - visual analogue scale of patient's pain, VEGF - vascular endothelial growth factor, WHR waist/hip ratio. 
Table II. The comorbidities in synovitis acne pustulosis hyperostosis osteitis syndrome patients

\begin{tabular}{|c|c|}
\hline Assessed parameter & $\begin{array}{c}\text { SAPHO } \\
\text { syndrome patients } \\
(n=46) \\
n(\%)\end{array}$ \\
\hline Hypothyroidism & $5(10.7)$ \\
\hline Hyperthyroidism & $1(2.2)$ \\
\hline Hypertension & $12(26.1)$ \\
\hline Ischemic heart disease & $3(6.5)$ \\
\hline $\begin{array}{l}\text { Chronic obstructive pulmonary } \\
\text { disease }\end{array}$ & $4(8.7)$ \\
\hline Diabetes & $4(8.7)$ \\
\hline Hepatitis B virus infection & $2(4.3)$ \\
\hline Depression & $3(6.5)$ \\
\hline Antiphospholipid syndrome & $1(2.2)$ \\
\hline Sjögren syndrome & $1(2.2)$ \\
\hline Cervical cancer & $1(2.2)$ \\
\hline
\end{tabular}

Data are presented as number (\%); $n$ - number of patients, SAPHO - synovitis acne pustulosis hyperostosis osteitis syndrome.

In our study serum IL-6 correlated positively with WHR, which is a marker of abdominal obesity.

We previously reported that serum IL-18 was higher in SAPHO patients with increased BMI [16]. Serum IL-18 is associated with atherosclerosis, which could suggest that SAPHO patients have increased risk of atherosclerosis stimulated by IL-18, and being overweight could be connected with increased secretion of IL-18 [16, 26].

A variety of studies have suggested that patients with PsA have an increased risk of MetS, which is a clustering of cardiovascular risk factors, such us obesity, hypertension, dyslipidemia, and insulin resistance $[17,18]$. There are no data concerning the risk of MetS in patients with SAPHO syndrome. Our study was the first to present the specific components of the MetS in SAPHO patients. We found that disease activity correlated positively with levels of TC and LDL-C, which are well-known markers of the risk of cardiovascular disease. This suggests an increased risk of cardiovascular disease in this group of patients.

Interleukin-23 is considered to be involved in the pathogenesis of SpA $[15,27]$. Interestingly, we found a positive correlation between serum IL-23 and HDL-C in our patients. This could suggest a protective effect of IL-23 on MetS risk in SAPHO patients. Lang et al. [28] explained that cholesterol metabolism interacts with the IL-23, IL-17 and granulocyte colony-stimulating factor (G-CSF) axis in hematopoietic stem cell mobilization and differentiation to inflammatory cells that participate in atherosclerosis in mice. The influ-
Table III. Treatment regimens used in synovitis acne pustulosis hyperostosis osteitis syndrome patients

\begin{tabular}{|lc|}
\hline Assessed parameter & $\begin{array}{c}\text { SAPHO } \\
\text { syndrome patients } \\
(n=46) \\
n(\%)\end{array}$ \\
\hline NSAIDs only & $8(17.4)$ \\
\hline NSAIDs with sulfasalazine & $19(41.3)$ \\
\hline NSAIDS with methotrexate & $19(41.3)$ \\
\hline $\begin{array}{l}\text { NSAIDs with sulfasalazine, and } \\
\text { antibiotics }\end{array}$ & $8(17.4)$ \\
\hline $\begin{array}{l}\text { NSAIDs with methotrexate, and } \\
\text { antibiotics }\end{array}$ & $10(21.7)$ \\
\hline
\end{tabular}

Data are presented as number (\%); $n$-number of patients, NSAIDS - nonsteroidal anti-inflammatory drugs, SAPHO - synovitis acne pustulosis hyperostosis osteitis syndrome.

ence of IL-23 on lipid profile in SAPHO requires further study.

Navarro-Milán et al. [29] observed an increase in TC and LDL-C plasma levels in patients with early rheumatoid arthritis (RA) after MTX treatment. Marques et al. [30] reported that MTX treatment resulted in higher accumulation of lipids in adipocytes which can synthesize TG. Additionally MTX contributed to adipocyte hypertrophy and dysfunction, which could explain the increased MetS prevalence in RA patients treated with MTX [30]. In PsA patients after 24-month treatment with MTX, Costa et al. [31] found that the distribution of subjects affected by MetS at different time periods according to treatment was not modified over time, although they expected MetS components to be reduced after anti-inflammatory treatment. Our results are consistent with these data. We observed increased TG and LDL-C levels and increased prevalence of MetS in SAPHO patients treated with MTX. This could suggest that in SAPHO patients MTX treatment promotes or exacerbates MetS.

In our study, $86.6 \%$ of patients had increased tracer uptake on bone scintigraphy in sternoclavicular joints. This is consistent with data that we have previously published and with data presented by other authors [4, 7, 8, 22, 32].

There is not much known about the comorbidities in the course of SAPHO. Valkema et al. [33] observed a relatively high prevalence of autoimmune diseases in SAPHO patients. Sabugo et al. [34] presented a case of SAPHO and hypothyroidism that was successfully treated with infliximab, which interestingly after that treatment had decreased levothyroxine requirements [34]. We previously presented a case report of recurrent deep vein thrombosis caused by antiphospholipid syndrome in woman with SAPHO [35]. In our current study, the most common comorbidities were 
hypothyroidism and diabetes, and additionally 1 patient had Sjögren syndrome. This could confirm the suggestion of Valkema et al. [33] that autoimmunity may play a role in the pathomechanism of SAPHO syndrome.

We also observed a high prevalence of depression in our patients. We did not find data about increased risk of depression in SAPHO, but other authors reported increased risk of depression in patients with psoriasis and PsA [36, 37]. Moreover, Lewinson et al. [37] confirmed that depression increased risk of PsA in patients with psoriasis. Possibly the same relationship occurs in SAPHO.

No standard treatment protocols of SAPHO syndrome are available and current treatment options are not evidenced-based due to the rarity of the disease. Non-steroid anti-inflammatory drugs are considered to be the first-line agents in SAPHO, but in our study they were effective only in some patients, which is consistent with data from other studies [4, 19, 22].

Propionibacterium acnes is probably an important trigger of SAPHO syndrome, although it has only been found occasionally in bacterial cultures [11-13]. Antibiotics showed a good response in $39.1 \%$ of our patients, and antibiotics could be useful in the treatment of SAPHO syndrome [11-13].

We also observed that the use of disease-modifying antirheumatic drugs, particularly MTX and sulphasalazine, has been beneficial in some patients, although ineffective in others [5, 22].

In conclusion, serum interleukin-23 protects, whereas methotrexate treatment stimulates selected components of the MetS in patients with SAPHO syndrome. Increased prevalence of autoimmune diseases and depression was observed in SAPHO syndrome patients. Antibiotics could be useful in the treatment of patients with SAPHO. The novelty of this study is a comprehensive assessment of the impact of disease activity, selected serum cytokines, and therapy on MetS components in patients with SAPHO syndrome.

\section{Acknowledgments}

This work was supported by a grant from the National Science Centre in Poland (DEC2011/03/B/NZ5/04192).

\section{Conflict of interest}

The authors declare no conflict of interest.

\section{References}

1. Chamot AM, Benhamou CL, Kahn MF, Beraneck L, Kaplan G, Prost A. Le syndrome acné pustulose hyperostose ostéite (SAPHO). Résultats d'une enquête nationale. 85 observations. Rev Rhum Mal Osteoartic 1987; 54: 187-96.
2. Kahn MF, Kahn MA. The SAPHO syndrome. Bailliere Clin Rheumatol 1994; 8: 333-62.

3. Schilling F, Kessler St. Das SAPHO syndrome: klinisch-rheumatologische und radiologische differenzierung und klassifizierung eines krankengutes von 86 fällen. Z Rheumatol. 2000; 59: 1-28.

4. Colina M, Govoni M, Orzincolo C, Trotta F. Clinical and radiological evolution of synovitis, acne, pulstulosis, hyperostosis and osteitis syndrome: a single center study of a cohort of 71 subjects. Arthritis Rheum 2009; 61: 813-21.

5. Hayem G, Bouchaud-Chabot A, Benali K, et al. SAPHO syndrome: a long-term follow-up study of 120 cases. Semin Arthritis Rheum 1999; 29: 159-71.

6. Przepiera-Będzak H, Brzosko I, Brzosko M. Skeletal changes during the course of pustulosis palmoplantaris: report of two cases. Pol Arch Med Wewn 2002; 107: 59-62.

7. Przepiera-Bedzak H, Brzosko I, Fliciński J, Samborski W, Brzosko M. SAPHO syndrome - clinical features. Pol Arch Med Wewn 2006; 116: 1172-7.

8. Salles M, Olive A, Perez-Andres R, et al. The SAPHO syndrome: a clinical and imaging study. Clin Rheumatol 2011; 30: 245-9.

9. Nitzsche EU. Nuclear medicine imaging for diagnosis of CRPS I. Handchir Mikrochir Plast Chir 2011; 43: 20-4.

10. Linke R, Kuwert T, Uder M, Forst R, Wuest W. Skeletal SPECT/CT of the peripheral extremities. AJR Am J Roentgenol 2010; 194: 329-35.

11. Assmann G, Kueck O, Kirchhoff T, et al. Efficacy of antibiotic therapy for SAPHO syndrome is lost after its discontinuation: an interventional study. Arthritis Res Ther 2009; 11: R140.

12. Govoni M, Colina M, Massara A, Trotta F. SAPHO syndrome and infections. Autoimmun Rev 2009; 8: 256-9.

13. Colina M, Trotta F. Antibiotics may be useful in the treatment of SAPHO syndrome. Mod Rheumatol 2014; 24: 697-8.

14. Przepiera-Będzak H, Fischer K, Brzosko M. Serum levels of angiogenic cytokines in psoriatic arthritis and SAPHO syndrome. Pol Arch Med Wewn 2013; 123: 297-302.

15. Przepiera-Będzak H, Fischer K, Brzosko M. Serum IL-6 and IL-23 levels and their correlation with angiogenic cytokines and disease activity in ankylosing spondylitis, psoriatic arthritis, and SAPHO syndrome. Mediators Inflamm 2015; 2015: 785705.

16. Przepiera-Będzak H, Fischer K, Brzosko M. Serum interleukin-18, fetuin-A, soluble intercellular adhesion molecule-1, and endothelin-1 in ankylosing spondylitis, psoriatic arthritis, and SAPHO syndrome. Int. J Mol Sci 2016; 17: 1255.

17. Mok CC, Ko GTC, Ho LY, Yu KL, Chan PT, To CH. Prevalence of atherosclerotic risk factors and the metabolic syndrome in patients with chronic inflammatory arthritis. Arthritis Care Research 2011; 63: 195-202.

18. Raychaudhuri SK, Chatterjee S, Nguyen C, Kaur M, Jialal I, Raychaudhuri SP. Increased prevalence of the metabolic syndrome in patients with psoriatic arthritis. Metabol Syndr Relat Disord 2010; 8: 331-4.

19. Garrett S, Jenkinson T, Kennedy LG, Whitelock H, Gaisford P, Calin A. A new approach to defining disease status in ankylosing spondylitis: the Bath Ankylosing Spondylitis Disease Activity Index. J Rheumatol 1994; 21: 2286-91.

20. Expert Panel on Detection, Evaluation, and Treatment of High Blood Cholesterol in Adults.. Executive Summary of The Third Report of The National Cholesterol Education Program (NCEP) Expert Panel on Detection, Evalua- 
tion, And Treatment of High Blood Cholesterol In Adults (Adult Treatment Panel III). JAMA 2001; 16: 2486-97.

21. Aljuhani F, Tournadre A, Tatar Z, et al. The SAPHO syndrome: a single-center study of 41 adult patients. J Rheumatol 2015; 42: 329-34.

22. Li C, Zuo Y, Wang J, et al. Synovitis, acne, pustulosis, hyperostosis and osteitis syndrome: a single centre study of a cohort of 164 patients. Rheumatology (Oxford) 2016; 55: 1023-30.

23. Hurtado-Nedelec $M$, Chollet-Martin $S$, Nicaise-Roland $P$, et al. Characterization of the immune response in the synovitis, acne, pustulosis, hyperostosis, osteitis (SAPHO) syndrome. Rheumatology 2008; 47: 1160-7.

24. Przepiera-Będzak H, Fischer K, Brzosko M. Extra-articular symptoms in constellation with selected serum cytokines and disease activity in spondyloarthritis. Mediators Inflamm 2016; 2016: 7617954.

25. Ellulu MS, Patimah I, Khaza'ai H, Rahmat A, Abed Y. Obesity and inflammation: the linking mechanism and the complications. Arch Med Sci 2017; 13: 851-63.

26. Blankenberg S, Luc G, Ducimetière P, et al.; PRIME Study Group. Interleukin-18 and the risk of coronary heart disease in European men: the Prospective Epidemiological Study of Myocardial Infarction (PRIME). Circulation 2003; 108: 2453-9.

27. Singh AK, Misra R, Aggarwal A. Th-17 associated cytokines in patients with reactive arthritis/undifferentiated spondyloarthropathy. Clin Rheumatol 2011; 30: 771-6.

28. Lang JK, Cimato TR. Cholesterol and hematopoietic stem cells: inflammatory mediators of atherosclerosis. Stem Cells Transl Med 2014; 3: 549-52.

29. Navarro-Millán I, Charles-Schoeman C, Yang S, et al. Changes in lipoproteins associated with methotrexate or combination therapy in early rheumatoid arthritis: results from the treatment of early rheumatoid arthritis trial. Arthritis Rheum 2013; 65: 1430-8.

30. Marques C, Teixeira D, Cunha A, et al. Methotrexate enhances 3T3-L1 adipocytes hypertrophy. Cell Biol Toxicol 2013; 29: 293-302.

31. Costa L, Caso F, Atteno M, et al. Impact of 24-month treatment with etanercept, adalimumab, or methotrexate on metabolic syndrome components in a cohort of 210 psoriatic arthritis patients. Clin Rheumatol 2014; 33: 833-9.

32. Przepiera-Będzak H, Cyryłowski L, Brzosko I, Zorga P, Brzosko $\mathrm{M}$. The imaging of sterno-clavicular joints in SAPHO syndrome. Post Nauk Med 2012; 25: 89-94.

33. Valkema PA, Luymes $\mathrm{CH}$, Witteveen JE, et al. High prevalence of autoimmune disease in the rare inflammatory bone disorder sternocostoclavicular hyperostosis: survey of a Dutch cohort. Orphanet J Rare Dis 2017; 12: 20.

34. Sabugo F, Liberman C, Niedmann JP, Soto L, Cuchacovich $M$. Infliximab can induce a prolonged clinical remission and a decrease in thyroid hormonal requirements in a patient with SAPHO syndrome and hypothyroidism. Clin Rheumatol 2008; 27: 533-5.

35. Przepiera-Będzak H, Brzosko M. Antiphospholipid syndrome with anti-2glicoprotein-1 antibodies as the cause of recurrent tibial vein thrombosis in SAPHO syndrome. Acta Dermatovenerol Croat 2016; 24: 305-6.

36. Wu J, Penfold RB, Primatesta P, et al. The risk of depression, suicidal ideation and suicide attempt in patients with psoriasis, psoriatic arthritis or ankylosing spondylitis. J Eur Acad Dermatol Venereol 2017; 31: 1168-75.

37. Lewinson RT, Vallerand IA, Lowerison MW, et al. Depression is associated with an increased risk of psoriatic arthritis among patients with psoriasis: a population-based study. J Invest Dermatol 2017; 137: 828-35. 